\title{
Astatine Facing Janus: Halogen Bonding vs. Charge-Shift Bonding
}

\author{
Serigne Sarr $^{1}$, Julien Pilmé ${ }^{2} \mathbb{D}$, Gilles Montavon ${ }^{3}$, Jean-Yves Le Questel ${ }^{1} \mathbb{D}$ and Nicolas Galland ${ }^{1, *}$ \\ 1 Laboratoire CEISAM, UMR CNRS 6230, Université de Nantes, 2 Rue de la Houssinière, 44322 Nantes, France; \\ Serigne.Sarr1@etu.univ-nantes.fr (S.S.); jean-yves.le-questel@univ-nantes.fr (J.-Y.L.Q.) \\ 2 Laboratoire de Chimie Théorique, UMR CNRS 7616, Sorbonne Université, 4 Place Jussieu, 75005 Paris, France; \\ julien.pilme@sorbonne-universite.fr \\ 3 Laboratoire SUBATECH, UMR CNRS 6457, IN2P3/EMN Nantes/Université de Nantes, 4 Rue Alfred Kastler, \\ 44307 Nantes, France; montavon@subatech.in2p3.fr \\ * Correspondence: nicolas.galland@univ-nantes.fr
}

Citation: Sarr, S.; Pilmé, J.;

Montavon, G.; Le Questel, J.-Y.;

Galland, N. Astatine Facing Janus: Halogen Bonding vs. Charge-Shift Bonding. Molecules 2021, 26, 4568. https://doi.org/10.3390/

molecules26154568

Academic Editor: Tanja van Mourik

Received: 29 June 2021

Accepted: 23 July 2021

Published: 28 July 2021

Publisher's Note: MDPI stays neutral with regard to jurisdictional claims in published maps and institutional affiliations.

Copyright: (c) 2021 by the authors. Licensee MDPI, Basel, Switzerland. This article is an open access article distributed under the terms and conditions of the Creative Commons Attribution (CC BY) license (https:/ / creativecommons.org/licenses/by/ $4.0 /)$.

\begin{abstract}
The nature of halogen-bond interactions was scrutinized from the perspective of astatine, potentially the strongest halogen-bond donor atom. In addition to its remarkable electronic properties (e.g., its higher aromaticity compared to benzene), $\mathrm{C}_{6} \mathrm{At}_{6}$ can be involved as a halogen-bond donor and acceptor. Two-component relativistic calculations and quantum chemical topology analyses were performed on $\mathrm{C}_{6} \mathrm{At}_{6}$ and its complexes as well as on their iodinated analogues for comparative purposes. The relativistic spin-orbit interaction was used as a tool to disclose the bonding patterns and the mechanisms that contribute to halogen-bond interactions. Despite the stronger polarizability of astatine, halogen bonds formed by $\mathrm{C}_{6} \mathrm{At}_{6}$ can be comparable or weaker than those of $\mathrm{C}_{6} \mathrm{I}_{6}$. This unexpected finding comes from the charge-shift bonding character of the $\mathrm{C}-\mathrm{At}$ bonds. Because charge-shift bonding is connected to the Pauli repulsion between the bonding $\sigma$ electrons and the $\sigma$ lone-pair of astatine, it weakens the astatine electrophilicity at its $\sigma$-hole (reducing the charge transfer contribution to halogen bonding). These two antinomic characters, charge-shift bonding and halogen bonding, can result in weaker At-mediated interactions than their iodinated counterparts.
\end{abstract}

Keywords: astatine; halogen-bond interactions; spin-orbit coupling; charge-shift bonds; QTAIM; ELF; local electrophilicity

\section{Introduction}

Many standard classifications in chemistry cross the group of p-elements, especially the chemical families known as pnictogens, chalcogens, and halogens. The pnictogen, chalcogen, and halogen elements are commonly involved in non-covalent interactions, sometimes gathered under the name of $\sigma$-hole interactions $[1,2]$. Bound to an electron-withdrawing group, these elements display a region of electron deficiency, the so-called $\sigma$-hole, which can induce highly directional attractive interactions with a nucleophilic region from another, or from the same, molecular entity. These interactions are better known, since the 2000s, as pnictogen, chalcogen, and halogen bonds, the latter being increasingly used in materials science, supramolecular chemistry, organocatalysis, chemical biology, and medicinal chemistry [3-10]. Among this framework, halobenzenes are an interesting class of halogen-bond donors, $\mathrm{R}-\mathrm{X}$, because halogen atoms $X$ can be easily introduced into a benzene ring at different positions. In addition, these compounds provide a convenient platform for introducing substituents and investigating, experimentally and theoretically, their effects on the ability of $\mathrm{X}$ to mediate halogen-bond interactions (i.e., halogen-bond tuning) [11-17]. Currently, it is commonly recognized that the interaction strength increases as $\mathrm{R}$ is more electron-withdrawing, and for a given $\mathrm{R}$, in the order $\mathrm{X}=\mathrm{F}<\mathrm{Cl}<\mathrm{Br}<\mathrm{I}$, following the trend in the halogens' polarizabilities (and decreasing electronegativities) [2,10,18]. 
Among the halogens, astatine has long been expected to be the strongest halogen-bond donor atom $[19,20]$, but this assumption is particularly challenging to prove experimentally, since astatine is the rarest element naturally occurring on Earth. Beyond the very small amounts available, which are produced in particle accelerators, the lack of suitable spectroscopic tools severely limits the investigations of astatine's chemical and physical properties [21]. Very recently, several of the current authors reported the first experimental characterization of halogen bonds (XBs) mediated by astatine [22]. That work and its following support a highest donating ability of astatine compared to iodine [23]. The adducts between astatine monoiodide (AtI) and ten Lewis bases were identified through the comparison of measured formation constants and those calculated using relativistic quantum mechanical methods. Indeed, astatine $(Z=85)$ is a heavy element and, as such, it is subject to significant relativistic effects. The scalar-relativistic effects are essentially associated with the relativistic mass increase of the electrons, resulting from their high speed near the nucleus. The main spin-dependent effect is the spin-orbit coupling (SOC), i.e., the interaction of the electron spin with magnetic fields generated by other charged particles in relative motion, leading to the coupling between electron spin and orbital momentum. The SOC effects can be rather important on the characteristics of XBs formed by astatine. In a theoretical study focused on XAt $\cdots \mathrm{NH}_{3}$ complexes $(\mathrm{X}=\mathrm{F}-\mathrm{At})$, the $\mathrm{SOC}$ was found to weaken the interaction by more than $20 \%$ when $X=F$ or At [24]. At-mediated XBs can be enhanced as well with the inclusion of the spin-orbit interaction in the relativistic calculations [25].

Using state-of-the-art relativistic quantum mechanical methods, Alvarez-Thon and co-workers have recently scrutinized how relativity affects the electronic structure of hexahalogened benzenes, $\mathrm{C}_{6} \mathrm{X}_{6}(\mathrm{X}=\mathrm{F}-\mathrm{At})$ [26]. As expected, the SOC had no or trifling effect on the aromaticity in $\mathrm{C}_{6} \mathrm{~F}_{6}, \mathrm{C}_{6} \mathrm{Cl}_{6}$, and $\mathrm{C}_{6} \mathrm{Br}_{6}$. Conversely, the influence became noticeable in $\mathrm{C}_{6} \mathrm{I}_{6}$ and had a dramatic effect in $\mathrm{C}_{6} \mathrm{At}_{6}$. Indeed, the significant contribution of the spin-orbit interaction to the current electronic flow around the molecular framework makes the hypothetical $\mathrm{C}_{6} \mathrm{At}_{6}$ molecule more aromatic than the archetypical aromatic benzene, according to the calculated ring current strengths. In this work we propose to study how significantly the SOC effect can impact on the ability of $\mathrm{C}_{6} \mathrm{At}_{6}$ to form XBs. More precisely, the use of quantum chemical topology (QCT) notably helps to probe the nature of C-At bonds. For comparison, the study of the effects of SOC on the iodinated analogue, $\mathrm{C}_{6} \mathrm{I}_{6}$, was also made. The disclosed trends were then tested through the study of another aromatic compound, in connection with the applications currently envisaged for the 211 radioisotope of astatine in nuclear medicine [21].

\section{Materials and Methods}

The two-component relativistic density functional theory (DFT), which was proved to be accurate for investigating At-containing systems [27,28], requires the replacement of the orbital representation by spinors that are complex vector functions of two components (2c). The Generalized Kohn-Sham (GKS) method, implemented in the Gaussian 16 rev. A.03 program [29], takes advantage of the relativistic pseudo-potentials containing scalar and spin-dependent terms to treat the electron correlation and the relativistic effects on an equal footing. In a recent benchmark study focusing on At-compounds [30], the PW6B95 hybrid functional clearly emerged as one of the best performing ones among 36 tested DFT functionals. Moreover, PW6B95 has also been validated as reliable for investigating compounds stabilized by At-mediated halogen bonds [22,23,25], notably according to results obtained with the gold-standard $\operatorname{CCSD}(\mathrm{T})$ method [24,31,32]. In the benchmark study, it was also noticed, regarding the complexes stabilized by At-mediated interactions, that results may be slightly improved by the inclusion of a dispersion correction [30]. The D3 version of Grimme's dispersion correction, using the Becke-Johnson damping function GD3BJ, was selected [33]. The small core pseudo-potential ECP60MDF was used for the At atoms, and the ECP28MDF one for the I atoms [34,35]. The explicitly treated electrons were described by a set of triple zeta quality basis sets, abbreviated as TZVPPD. It includes the dhf-TZVPPD-2c basis sets for the At and I atoms [36], and the def2-TZVPP basis sets 
for the remaining atoms [37], with diffuse functions being added for non-H atoms [38]. To evaluate the SOC effects $(\Delta \mathrm{SO})$ on the properties of the studied species, geometry optimizations and frequency calculations were performed at both the 2c-relativistic DFT level and the scalar-relativistic DFT level (the one-electron spin-orbit terms were removed from the pseudo-potentials). Vibrational harmonic frequencies were used to establish the nature of the structures (minima vs. transition states). The energies of the $\mathrm{XB}$ complexes were corrected from the basis set superposition error (BSSE) using the counterpoise (CP) method [39], and the corresponding interaction energies were calculated using the supermolecule approach. In order to assess the reliability of previously calculated geometries and interaction energies, $\mathrm{CP}$-corrected MP2/TZVPPD geometry optimizations were performed at the scalar-relativistic (sr) level. Further sr-MP2/TZVPPD and 2c-MP2/TZVPPD singlepoint calculations, using the resolution of the identity technique in the TURBOMOLE program package [40], were respectively performed on sr- and 2c-PW6B95/TZVPPD geometries. Note that the core electrons were frozen for all MP2 calculations (including the semi-core $4 s 4 p 4 d$ electrons of I and $5 s 5 p 5 d$ electrons of At). For calculating the local electrophilicity of the studied species, we used values obtained by the finite difference method [41]. The Fukui function for localizing electrophilic sites, $f^{+}(r)$, is obtained as:

$$
f^{+}(r) \approx \rho_{\mathrm{N}+1}(r)-\rho_{\mathrm{N}}(r)
$$

where $\rho_{\mathrm{N}}$ and $\rho_{\mathrm{N}+1}$ are the electron densities of the neutral species ( $N$ electrons) and of the corresponding anion ( $N+1$ electrons) at the geometry of the neutral species. Furthermore, the electronegativity, $\chi=\frac{1}{2}(\mathrm{IE}+\mathrm{EA})$, and the hardness, $\eta=(\mathrm{IE}-\mathrm{EA})$, were obtained from the vertical ionization energy (IE) and electron affinity (EA) values.

Introduced by Becke and Edgecombe [42], the electron localization function (ELF) is a signature of the distribution of electronic pairs. The analysis of its topology is a powerful tool for the characterization of bonding schemes [43]. The physical space is divided into electronic volumes or basins, which are localized around the maxima of the function and are separated by zero flux surfaces. The ELF partition assigns the electron density between core basins around nuclei $\mathrm{A}, \mathrm{C}(\mathrm{A})$, and valence basins. The latter are divided into non-bonding basins, $\mathrm{V}(\mathrm{A})$, usually corresponding to lone-pairs, and bonding basins, $\mathrm{V}\left(\mathrm{A}_{1}, \mathrm{~A}_{2}\right)$, characterizing the covalent character of the bond between two atoms, $\mathrm{A}_{1}$ and $A_{2}$. The spatial distribution of the valence basins closely matches the non-bonding and bonding domains of the valence shell electron pair repulsion (VSEPR) theory [44]. The integration of the electron density over the volume of the basins provides the average basin populations, which can be understood as arising from Lewis resonant structures [45]. The statistical analysis of basin populations through the definitions of the variance and the covariance matrices, provides information about the electron delocalization between basins. Furthermore, it was found from experimental and theoretical works that the quantum theory of atoms in molecules (QTAIM), formulated by Bader, provides a route to analyze, evaluate, and classify the nature of chemical bonds and interactions [46-48]. In the QTAIM theory, the function of interest is the electron density $\rho(r)$. Each atom within a molecule corresponds to a basin, and the integration of the electron density over the basin volume provides an atomic population. The critical points of the electron density and their connectivity provide a characterization of the topology. The stationary point of the electron density along the line of the minimum electron density connecting two atoms, named the bond critical point (BCP), plays a central role in the QTAIM classification [49]. For example, the electron density at the $\mathrm{BCP}, \rho_{\mathrm{b}}$, is in general large in the case of "shared-shell" interactions (mainly covalent bonds) and generally lower than 0.10 a.u. in the case of "closed-shell" interactions (e.g., ionic bonds and weak interactions) [47,50]. Furthermore, a negative value of the Laplacian of the density, $\nabla^{2} \rho_{\mathrm{b}}$, indicates a local concentration of charge at the BCP, which is typical of shared-shell interactions. Conversely, a positive value of $\nabla^{2} \rho_{\mathrm{b}}$ indicates a depletion of charge that characterizes closed-shell interactions [49]. Another widely used descriptor is the delocalization index (DI), noted $\delta(\mathrm{A}, \mathrm{B})$. It measures the electron pair covalently sharing between two topological atoms A and B [51]. Details on 
the extension of the ELF and QTAIM topological analyses in the framework of 2c-relativistic DFT calculations can be found in $[32,52,53]$. All the topological analyses were carried out using a modified version of the TopChem2 program [54].

\section{Results and Discussion}

As indicated previously, we first sought to reveal the relativistic effects on the bonding patterns in the $\mathrm{C}_{6} \mathrm{At}_{6}$ species and also in $\mathrm{C}_{6} \mathrm{I}_{6}$ for comparative purposes. We will focus more specifically on the influence of the spin-orbit interaction, at the origin of the significant effect shown by Alvarez-Thon and co-workers (i.e., perastatobenzene becoming more aromatic than benzene) [26]. The tools of QCT, and especially the QTAIM and ELF topological analyses, have previously demonstrated their benefits for such studies [55-59].

\subsection{Topological Analyses of the $C_{6} X_{6} X B$ Donors}

Figure 1 shows the ELF localization domains determined for $\mathrm{C}_{6} \mathrm{At}_{6}$, which is also representative of the topology obtained for $\mathrm{C}_{6} \mathrm{I}_{6}$. Each atom has one core basin, $\mathrm{C}(\mathrm{C})$ for the carbon atoms and $C(X)$ for the halogen atoms. One bonding basin is found between each pair of adjacent carbon atoms, $\mathrm{V}(\mathrm{C}, \mathrm{C})$, as well as between the bounded carbon and halogen atoms, $\mathrm{V}(\mathrm{C}, \mathrm{X})$. Finally, each halogen atom displays one non-bonding valence basin, $\mathrm{V}(\mathrm{X})$, describing all its lone-pairs. The electron populations of most ELF basins and some other descriptors calculated at the 2c-PW6B95-D3/TZVPPD level of theory for $\mathrm{C}_{6} \mathrm{At}_{6}$ and $\mathrm{C}_{6} \mathrm{I}_{6}$ are gathered in Table 1.

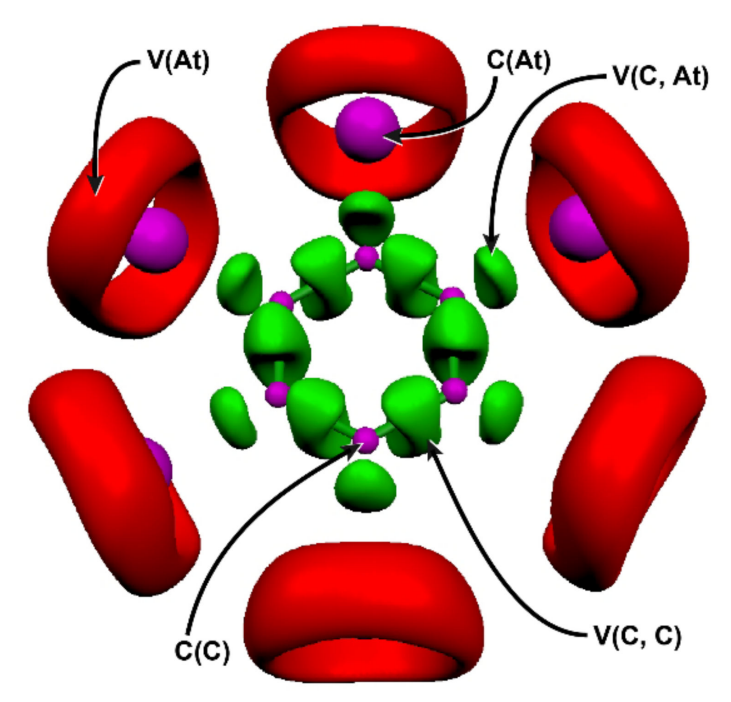

Figure 1. ELF localization domains for the $\mathrm{C}_{6} \mathrm{At}_{6}$ species (ELF isosurface $\left.=0.75\right)$ at the 2c-PW6B95D3/TZVPPD level of theory. Color code: magenta for core basins, red for valence non-bonding basins, and green for bonding basins.

Table 1. ELF electron population analysis of $\mathrm{C}_{6} \mathrm{X}_{6}$ species $(X=I$, At) obtained at the 2c-PW6B95D3/TZVPPD level of theory.

\begin{tabular}{ccccccc}
\hline & $\mathbf{V}(\mathbf{C}, \mathbf{C}): \overline{\mathbf{N}}$ & $\mathbf{V}(\mathbf{C}, \mathbf{C}): \boldsymbol{\lambda}$ & $\begin{array}{c}\mathbf{C}(\mathbf{X})+\overline{\mathbf{N}} \\
\mathbf{V}(\mathbf{X}): \overline{\mathbf{N}}\end{array}$ & $\mathbf{V}(\mathbf{X}): \boldsymbol{\sigma}^{\mathbf{2}}$ & $\mathbf{V}(\mathbf{C}, \mathbf{C}): \overline{\mathbf{N}}$ & $\mathbf{V}(\mathbf{C}, \mathbf{X}): \boldsymbol{\lambda}$ \\
\hline $\mathrm{X}=\mathrm{I}$ & 2.90 & 0.48 & 24.30 & 1.03 & 1.72 & 0.61 \\
$\Delta \mathrm{SO}^{\mathrm{a}}$ & +0.03 & -0.00 & -0.22 & -0.00 & -0.08 & +0.00 \\
$\mathrm{X}=\mathrm{At}$ & 2.87 & 0.48 & 24.34 & 1.12 & 1.70 & 0.63 \\
$\Delta \mathrm{SO}^{\mathrm{a}}$ & +0.00 & +0.00 & +0.01 & +0.00 & -0.01 & +0.01 \\
\hline${ }^{a}$ Defined as the difference between the results of 2c-PW6B95-D3/TZVPPD and sr-PW6B95-D3/TZVPPD calculations.
\end{tabular}


The populations for $\mathrm{C}(\mathrm{X})+\mathrm{V}(\mathrm{X}), \sim 24.3 \mathrm{e}$, were very close to the sum of 18 core electrons (i.e., the outermost core electrons that were not included in the pseudo-potential) and 6 electrons associated to three lone-pairs for each halogen. The $\mathrm{V}(\mathrm{C}, \mathrm{X})$ bonding basins showed populations, $\sim 1.7 \mathrm{e}$, below the typical value of two electrons expected for a pure single covalent bond. This depleted electron population indirectly points to an additional component to covalent bonding. However, for C-At bonds, it cannot be attributed to an ionic character as we will see hereafter. As expected, the populations of the $\mathrm{V}(\mathrm{C}, \mathrm{C})$ basins, 2.9 e, were intermediate between those of a single and a double bond ( 2 vs. 4 electrons). For instance, the bonding electron population for benzene $C-C$ bonds is known from previous ELF analyses to be 2.8 e $[60,61]$. In the framework of ELF topological analyses, a measure of electron delocalization is provided by the electron population $\overline{\mathrm{N}}$ of the bonding basins, but also by its variance $\sigma^{2}$. The variance for an ELF basin represents the electron fluctuation between the basin and the rest of the molecule, and it is useful to define the relative fluctuation $\lambda=\sigma^{2} / \overline{\mathrm{N}}$. In the benzene molecule, characterized by a highly delocalized $\pi$ system, the relative fluctuation of the $V(C, C)$ basins is about $46 \%[60,61]$. Similar values $(48 \%)$ were obtained for the $V(C, C)$ basins in $C_{6} A_{6}$ and $C_{6} I_{6}$ species.

The most striking result is the much higher value of $\lambda$ for the $V(C, X)$ basins and, in particular, for the $\mathrm{C}$-At bond: $63 \%$ of the 1.70 bonding electrons fluctuated between each $\mathrm{V}(\mathrm{C}, \mathrm{At})$ basin and other regions of the molecule. For a $\sigma$ bond, a large variance in addition to a depleted basin population is indicative of a significant charge-shift (CS) bonding character. CS bonds have been proposed as a third bonding modality, alongside the two traditional covalent and ionic bond families [62,63]. Considering a bond of the general type $\mathrm{R}-\mathrm{X}$, the bonding itself owes its stability from large and dynamic fluctuations of the bonding electron-pair, which can be pictured through resonance between the covalent and ionic Lewis structures: $\mathrm{R}\left|\mathrm{X}^{+} \leftrightarrow \mathrm{R}-\mathrm{X} \leftrightarrow{ }^{+} \mathrm{R}\right| \mathrm{X}^{-}$. The CS mechanism originates in Pauli repulsions between the bonding electrons and the lone-pairs adjacent to the bond, which have the same symmetry as the bond (here, the halogen $\sigma$ lone-pair). This effect weakens the covalent contribution to the bonding and is referred to as the lone pair bondweakening effect (LPBWE). The bond stabilization is achieved by an optimal covalent-ionic mixing, resulting in a tremendous resonance energy. The elements that are prone to CS bonding are compact electronegative and/or lone-pair-rich atoms, albeit with moderate electronegativities [64]. Astatine has notably a demonstrated potential to form bonds of CS type $[25,52,59]$, notably with carbon atoms [32,52].

More decisive elements are provided by QTAIM analyses. Some descriptors of the nature of $C-X$ bonds are presented in Table 2, while those related to $C-C$ bonds are gathered in Table S1 in Supplementary Materials. It is worth noting that, at the BCP of the $\mathrm{C}-\mathrm{C}$ bonds in $\mathrm{C}_{6} \mathrm{At}_{6}$ and $\mathrm{C}_{6} \mathrm{I}_{6}$ species, the electron density was larger than $0.2 \mathrm{a}$.u. and the Laplacian of the electron density was negative. According to the standard QTAIM classification $[47,50]$, these are two characteristics of shared-shell interactions, i.e., mainly covalent bonds. Furthermore, the delocalization index, which is considered as a measure of the sharing of electron-pairs between atoms $[50,65]$, is very informative regarding the nature of $C-C$ bonds. The value of $\delta(C, C), \sim 1.36$, was thereby intermediate between the formal bond orders of a single and a double bond, supporting the picture of aromatic rings built of conjugated covalent $\mathrm{C}-\mathrm{C}$ bonds. The situation regarding the $\mathrm{C}-\mathrm{I}$ bonds also seemed rather clear, according to the results of Table $2 . \nabla^{2} \rho_{\mathrm{b}}$ was negative and, although the electron density was somewhat weak at the BCP $\left(\rho_{\mathrm{b}}=0.13\right.$ a.u. $)$, the $\delta(\mathrm{C}, \mathrm{I})$ value of 1.11 also supported their designation as covalent single bonds. Conversely, the QTAIM descriptors for the $\mathrm{C}-\mathrm{At}$ bonds may appear confusing. At the BCP and according to the standard QTAIM classification, the positive value of $\nabla^{2} \rho_{\mathrm{b}}$ and the value of 0.10 a.u. of $\rho_{\mathrm{b}}$ would indicate closed-shell interactions between $\mathrm{C}$ and At atoms, i.e., bonds were dominated by an ionic character. However, this view is contradicted by the computed atomic charge for astatine, which was not so large, $0.19 \mathrm{e}$, and identical to that of iodine in the covalent $\mathrm{C}-\mathrm{I}$ bonds of $\mathrm{C}_{6} \mathrm{I}_{6}$. Furthermore, the delocalization index is found in the literature to have a value approaching to zero for ionic bonds, meanwhile it shows 
values approaching the formal bond order for covalent and CS bonds $[65,66]$. The value of $\delta(C, A t), 0.99$, disagrees with the picture of a mainly ionic bond. In fact, an important feature was disclosed: the nature of these C-At bonds did not fit with the standard QTAIM classification. This is a characteristic of CS bonds $[63,67]$.

Table 2. Selected QTAIM descriptors (in a.u.) obtained at the 2c-PW6B95-D3/TZVPPD level of theory for $\mathrm{C}-\mathrm{X}$ bonds in $\mathrm{C}_{6} \mathrm{X}_{6}$ species $(\mathrm{X}=\mathrm{I}$, At).

\begin{tabular}{cccccc}
\hline & $\rho_{\mathbf{b}}{ }^{\mathbf{b}}$ & $\nabla^{2} \rho_{\mathbf{b}}{ }^{\mathbf{c}}$ & $\left|\mathbf{V}_{\mathbf{b}}\right| / \mathbf{G}_{\mathbf{b}} \mathbf{d}^{\mathrm{d}}$ & $\delta(\mathbf{C}, \mathbf{X})^{\mathbf{e}}$ & $\mathbf{q}(\mathbf{X})^{\mathbf{f}}$ \\
\hline $\mathrm{X}=\mathrm{I}$ & 0.13 & -0.03 & 2.13 & 1.11 & 0.19 \\
$\Delta \mathrm{SO}^{\mathrm{a}}$ & -0.00 & +0.00 & -0.01 & -0.01 & -0.00 \\
$\mathrm{X}=\mathrm{At}$ & 0.10 & 0.04 & 1.82 & 0.99 & 0.19 \\
$\Delta \mathrm{SO}^{\mathrm{a}}$ & -0.01 & +0.01 & -0.07 & -0.09 & -0.00
\end{tabular}

a Defined as the difference between the results of 2c-PW6B95-D3/TZVPPD and sr-PW6B95-D3/TZVPPD calculations

${ }^{b}$ Electron density at the BCP. ${ }^{c}$ Laplacian of the electron density at the BCP. ${ }^{d}$ Ratio between the potential energy density and the (positive definite) kinetic energy density at the BCP. ${ }^{\mathrm{e}}$ Delocalization index. ${ }^{\mathrm{f}}$ Atomic charge.

The ability of chemical elements to form CS bonds originates in part from the compactness of their valence orbitals [62]. The SOC enhances the astatine propensity for CS bonding [52,59], most probably due to the dominant shrinkage of the $6 \mathrm{p}_{1 / 2}$ shell upon inclusion of SOC, by $\sim 0.2 \AA$ with respect to the $6 \mathrm{p}_{\mathrm{z}}$ orbital [68]. It is therefore of interest to scrutinize the SOC effects on the topological descriptors in order to assess the CS character of $\mathrm{C}-\mathrm{At}$ bonds in $\mathrm{C}_{6} \mathrm{At}_{6}$. In Table 2, the SOC effect $(\triangle \mathrm{SO})$ is defined as the difference between the results of 2c-PW6B95-D3/TZVPPD and sr-PW6B95-D3/TZVPPD calculations. The CS mechanism is associated to a weakening of the covalent contribution to the bonding. In the QTAIM approach, the ratio between the potential $(\mathrm{V})$ and positive definite kinetic (G) energy densities at the $B C P,\left|V_{b}\right| / G_{b}$, reflects the magnitude of covalency $[50,69]$. This ratio decreased upon SOC by $\sim 4 \%$, and the electron density, too, by $\sim 11 \%$ at the BCP (Table 2). The synchronized increase in $\nabla^{2} \rho_{\mathrm{b}}$ widened the gap with the QTAIM category of covalent bonds (i.e., shared-shell interaction). Further clues are provided by looking at the SOC effects on the ELF descriptors (Table 1). Associated to a slight decrease in the electron population of $\mathrm{V}(\mathrm{C}, \mathrm{At})$, an increase by $\sim 1 \%$ of the relative fluctuation for the bonding basin was obtained, in line with an increased covalent-ionic resonance. All these changes, although quantitatively moderate, support a noticeable CS character for C-At bonds in $\mathrm{C}_{6} \mathrm{At}_{6}$, enhanced with the spin-orbit interaction.

The Pauli repulsion operating between bonding and non-bonding $\sigma$ electrons is a physical origin of CS bonding [62,63]. Because its lone-pairs were involved, consequences are expected on the halogen atom's ability to act as a Lewis base or as a Lewis acid in the case of $\mathrm{XB}$ interactions. The conceptual density functional theory provides appealing and generalpurpose models for chemical reactivity. Several of the current authors recently proposed to use the local electrophilicity $\omega^{+}(r)$ to characterize $\sigma$-hole interactions, and more precisely $\omega^{+} \mathrm{S}$,max , which is the maximum value at the $\sigma$-hole on the molecular surface [31]. $\omega^{+} \mathrm{S}$,max is intended to probe the charge transfer contribution to the formation of $\mathrm{XB}$ interactions. $\omega^{+}(r)$ is defined as the product between the global electrophilicity index $\omega\left(\chi^{2} / 2 \eta\right)$ and the $f^{+}(r)$ Fukui function, which shows the distribution of an infinitesimal charge added to the system [41]. A high value of $\omega^{+}(r)$ indicates therefore an electrophilic zone. Figure $\mathrm{S} 1$ in the Supplementary Materials displays $\omega^{+}(r)$ at the molecular surface of $\mathrm{C}_{6} \mathrm{At}_{6}$ (and $\mathrm{C}_{6} \mathrm{I}_{6}$ ), highlighting the structure of the $\sigma$-holes at the astatine (and iodine) sites. It is worth noting that $\omega^{+} \mathrm{S}$, max was demonstrated to be a better descriptor for anticipating the SOC effects on XBs mediated by astatine than the well-known $V_{\mathrm{S}, \max }$ descriptor, i.e., the maximum value of the molecular electrostatic potential calculated at the $\sigma$-hole $[24,25]$. Associated with the strengthening upon SOC of the CS character of C-At bonds in $\mathrm{C}_{6} \mathrm{At}_{6}$, the local electrophilicity at the astatine $\sigma$-hole significantly decreased, by $\sim 20 \%$ according to the $\omega^{+}{ }_{S, \max }$ descriptor (Figure S1). Next, we studied how the SOC effect on the nature of C-At bonds was transposed on $\mathrm{XB}$ interactions involving $\mathrm{C}_{6} \mathrm{At}_{6}$ (and $\mathrm{C}_{6} \mathrm{I}_{6}$ for comparison purpose). 


\section{2. $\mathrm{C}_{6} \mathrm{X}_{6} \cdots \mathrm{NMe}_{3}$ Complexes}

In this section, we consider $\mathrm{XB}$ interactions between hexahalogenated benzene derivatives $\mathrm{C}_{6} \mathrm{X}_{6}(\mathrm{X}=\mathrm{I}$ or $\mathrm{At})$ and trimethylamine $\left(\mathrm{NMe}_{3}\right)$. $\mathrm{NMe}_{3}$ was selected since it is a strong Lewis base, widely used in studies dedicated to halogen bonding. The geometries of the $\mathrm{X}_{5} \mathrm{C}_{6}-\mathrm{X} \cdots \mathrm{NMe}_{3}$ systems $(\mathrm{X}=\mathrm{I}, \mathrm{At})$ were optimized at the scalar relativistic PW6B95D3/TZVPPD level of theory as well at the counterpoise-corrected (CP) MP2/TZVPPD level of theory. In order to evaluate the SOC effects $(\triangle \mathrm{SO})$ on the XBs, 2c-PW6B95-D3 calculations were performed as well on the $\mathrm{X}_{5} \mathrm{C}_{6}-\mathrm{X} \cdots \mathrm{NMe}_{3}$ complexes $(X=\mathrm{I}, \mathrm{At}) . \Delta \mathrm{SO}$ was estimated as the difference between the 2c-PW6B95-D3/TZVPPD and sr-PW6B95-D3/TZVPPD results. The latter can be compared to the results obtained from single-point MP2 calculations, i.e., 2c-MP2/TZVPPD/ / 2c-PW6B95-D3/TZVPPD and sr-MP2/TZVPPD//sr-PW6B95D3/TZVPPD. The results are presented in Table 3.

Table 3. PW6B95-D3/TZVPPD and MP2/TZVPPD counterpoise corrected interaction energies and related parameters: interaction distances, lengthening of $\mathrm{C}-\mathrm{X}$ bonds upon complexation, and interaction angles, for the $\mathrm{X}_{5} \mathrm{C}_{6}-\mathrm{X} \cdots \mathrm{NMe}_{3}$ complexes $(X=I, \mathrm{At})$.

\begin{tabular}{|c|c|c|c|c|c|}
\hline & & $\Delta E^{\mathrm{CP}}(\mathrm{kJ} / \mathrm{mol})$ & $d_{\mathrm{X}} \ldots \mathrm{N}_{\mathrm{N}}(\AA)$ & $\Delta d_{\mathrm{C}-\mathrm{X}}(\AA)$ & $\alpha_{\mathrm{CXN}}\left(^{\circ}\right)$ \\
\hline \multirow{2}{*}{ sr-PW6B95-D3 } & $\mathrm{I}-\mathrm{XB}$ & -32.6 & 2.835 & 0.026 & 179.8 \\
\hline & At-XB & -40.9 & 2.826 & 0.036 & 179.7 \\
\hline \multirow{2}{*}{ sr-MP2 } & $\mathrm{I}-\mathrm{XB}$ & -32.6 & $2.799^{a}$ & $0.028^{a}$ & $179.7^{\mathrm{a}}$ \\
\hline & At-XB & -32.6 & $2.800^{\mathrm{a}}$ & $0.037^{\mathrm{a}}$ & $179.8^{\mathrm{a}}$ \\
\hline \multirow{5}{*}{ 2c-PW6B95-D3 } & $\mathrm{I}-\mathrm{XB}$ & -32.1 & 2.842 & 0.024 & 180.0 \\
\hline & $\Delta S O$ & 0.5 & 0.007 & -0.002 & 0.2 \\
\hline & & & & & \\
\hline & At-XB & -36.0 & 2.895 & 0.019 & 179.5 \\
\hline & $\Delta \mathrm{SO}$ & 4.9 & 0.069 & -0.017 & -0.2 \\
\hline \multirow{5}{*}{ 2c-MP2 } & $\mathrm{I}-\mathrm{XB}$ & -35.3 & - & - & - \\
\hline & $\Delta \mathrm{SO}^{\mathrm{b}}$ & 0.3 & - & - & - \\
\hline & & & - & - & - \\
\hline & At-XB & -39.9 & - & - & - \\
\hline & $\Delta \mathrm{SO}^{\mathrm{b}}$ & 3.6 & - & - & - \\
\hline
\end{tabular}

All the studied systems exhibited a $C_{s}$ symmetry. The $C, X$, and $N$ atoms were almost aligned, i.e., the angle between the $C, X$, and $N$ atoms was close to $180^{\circ}$. Moreover, the interaction distances, $d_{X} \ldots \mathrm{N}$, were shorter than the sum of the van der Waals radii of $\mathrm{N}$ and $\mathrm{X}$, with $\mathrm{X}=\mathrm{I}$, At (a radius of $2.02 \AA$, based on sr-calculations [70], is assumed for astatine). These geometric features were characteristic of $\mathrm{XB}$ interactions. The sr-PW6B95D3/TZVPPD results were found to be in good agreement with the sr-MP2/TZVPPD ones. The interaction energies were slightly weaker, by $\sim 3 \mathrm{~kJ} / \mathrm{mol}$, and consequently slightly longer interaction distances were predicted, by $\sim 0.03 \AA$ ( $1 \%)$. The agreement was even better if one considers the values of the $\mathrm{C}-\mathrm{X}$ bond lengthening upon complexation or the values of the interaction angles. The $X B$ mediated by astatine (At- $X \mathrm{~B})$ was stronger than the $X B$ involving the iodine atom (I-XB), the difference of interaction energy being of $\sim 8 \mathrm{~kJ} / \mathrm{mol}$. This trend was consistent with the assumption that an $\mathrm{XB}$ interaction strengthens with the increase in the polarizability and with the decrease in the electronegativity of the halogen element involved in the interaction.

The effects of the SOC were significantly different according to the halogen atom involved in the $\mathrm{XB}$. Regarding I-XB, the interaction energy was negligibly affected $(1 \%)$ as well as the interaction distance, according to the 2c-PW6B95-D3 calculations. This was not the case for At-XB. The consideration of the SOC yielded a weakening of the interaction 
energy by $4.9 \mathrm{~kJ} / \mathrm{mol}$, i.e., $12 \%$ (Table 3). The MP2 calculations consistently predicted a weakening of $8 \%$. These results agreed with a lengthening of the At $\cdots \mathrm{N}$ interaction distance that was ten times greater than in the case of the I-XB (0.069 $\AA$ vs. $0.007 \AA)$. It is worth noting that the reduced ability of astatine to form $\mathrm{XB}$ interactions was expected from the previous discussion of the SOC effect on the nature of the C-At bond. Because the SOC enhances its CS character, the local electrophilicity was reduced at the astatine's $\sigma$-hole according to the calculated $20 \%$ decrease in $\omega^{+}$s,max. In the same vein, it is worth noting that the $V_{\mathrm{S}, \max }$ descriptor, commonly used to quantify the $\sigma$-hole strength $[2,18]$, was reduced as well by $\sim 6 \%$ when SOC was taken into account. Hence, both descriptors agreed with a decreased XB donating ability of astatine.

The weakening of the halogen bond donating ability of astatine upon inclusion of SOC led to a reduced energetic gap by comparison with the corresponding XB mediated by iodine. Thus, the At-XB was $3.9 \mathrm{~kJ} / \mathrm{mol}$ stronger than the $\mathrm{I}-\mathrm{XB}$ at the $2 \mathrm{c}-$ PW6B95-D3/TZVPPD level of theory, and the corresponding value was $4.6 \mathrm{~kJ} / \mathrm{mol}$ at the 2c-MP2/TZVPPD//2c-PW6B95-D3/TZVPPD level of theory (Table 3). Hence, the hexaastatobenzene appears, at first, as a better XB donor than the hexaiodobenzene, even when the relativistic spin-orbit interaction is taken into account in quantum mechanical calculations. However, it has been shown in a previous study that, depending on the nature of the interacting Lewis base, the $\mathrm{CAt}_{4}$ species may or may not form stronger $\mathrm{XBs}$ than those formed by $\mathrm{CI}_{4}$ [32]. With the aim of verifying this behavior in the case of $\mathrm{C}_{6} \mathrm{At}_{6}$, we planned to study interactions with other Lewis bases. We realized that $C_{6} X_{6}$ species $(X=I$, At) were indeed Lewis bases through their $\pi$ systems, acting as acceptor. In the next section, we extend the investigations by the consideration of $\mathrm{XB}$ complexes formed between two hexahalogenated benzenes.

\section{3. $\mathrm{C}_{6} \mathrm{X}_{6}{ }^{\cdots} \mathrm{C}_{6} Y_{6}$ Complexes}

In the $\mathrm{XB}$ complexes formed by two hexahalogenated benzenes (i.e., $\mathrm{C}_{6} \mathrm{X}_{6}$ and $\mathrm{C}_{6} \mathrm{Y}_{6}$ with $\mathrm{X}, \mathrm{Y}=\mathrm{I}, \mathrm{At}), \mathrm{C}_{6} \mathrm{X}_{6}$ represents the $\mathrm{XB}$ donor, whereas $\mathrm{C}_{6} \mathrm{Y}_{6}$ acts as the Lewis base $(\mathrm{XB}$ acceptor). Note that some similarities exist with the dimers of benzene, $\left(\mathrm{C}_{6} \mathrm{H}_{6}\right)_{2}$, which have been widely studied as models of the interactions involving aromatic rings $(\pi-\pi, \pi$-hydrogen bond interactions) [71,72]. The accurate description of $\pi-\pi$ interactions represents, as well, a challenge for the development of cost-effective quantum chemistry methods [73,74]. In our investigation of the $\mathrm{C}_{6} \mathrm{X}_{6} \cdots \mathrm{C}_{6} \mathrm{Y}_{6}$ heterodimers, we left aside the question of $\pi-\pi$ interactions (so-called sandwich and parallel-displaced structures) to focus on the structures stabilized by $\mathrm{XB}$ interactions. We will consider and compare the interactions mediated by iodine $(\mathrm{X}=\mathrm{I}$, $\mathrm{Y}=\mathrm{At})$ and by astatine $(\mathrm{X}=\mathrm{At}, \mathrm{Y}=\mathrm{I})$. The structure common to both types of interaction adopts a T-shaped tilted (TT) conformation with $\mathrm{C}_{\mathrm{s}}$ symmetry, similar to the one described for the $\mathrm{C}_{6} \mathrm{H}_{6}$ dimers. No stable T-shaped (T) conformation could be evidenced. Note that the TT structure competes to be the most stable conformation in $\left(\mathrm{C}_{6} \mathrm{H}_{6}\right)_{2}$ [74], and the stabilization of the TT conformation was here achieved through two interactions (see Figure 2). The first one $(X \cdots Y)$ occurred between one halogen atom of the $X B$ donor $\left(C_{6} X_{6}\right.$ with $\left.X=I, A t\right)$ and the negative belt of a halogen atom in $\mathrm{C}_{6} \mathrm{Y}_{6}(\mathrm{Y}=\mathrm{At}, \mathrm{I})$. The second interaction $(\mathrm{X} \cdots \mathrm{C})$ arose between another $\mathrm{X}$ atom and a part of the $\pi$ system of $\mathrm{C}_{6} \mathrm{Y}_{6}$ located at the vertical of a carbon atom, owing to the structural constraints induced by the $\mathrm{X} \cdots \mathrm{Y}$ interaction and the rigidity of the $\mathrm{C}_{6} \mathrm{X}_{6}$ monomer.

At the scalar-relativistic level of theory, the PW6B95-D3/TZVPPD optimized geometries were found in good agreement with the ones obtained from counterpoise-corrected MP2/TZVPPD calculations (cf. Table S2 in Supplementary Materials). The distances corresponding to the $\mathrm{X} \cdots \mathrm{Y}$ interactions $\left(d_{\mathrm{X}} \cdots \mathrm{Y}\right)$ were slightly shorter, on average by $2 \%$, whereas the distances corresponding to the $X \cdots C$ interactions $\left(d_{X} \ldots c_{C}\right)$ appeared a bit longer, by $4 \%$. The structures of the dimers computed at the 2c-PW6B95-D3/TZVPPD level of theory are presented in Figure 2. The $d_{X} \ldots \mathrm{Y}$ and $d_{\mathrm{X}} \ldots \mathrm{C}_{\mathrm{C}}$ distances were, at least, $4 \%$ shorter than the sum of the van der Waals radii of the atoms involved in these interactions. The displayed interaction angles, of approximately $160^{\circ}$, significantly deviated from the optimum value of 
$180^{\circ}$, certainly because of the structural constraints mentioned above (accommodating two interactions plus the rigidity of the monomers). These $\mathrm{C}_{6} \mathrm{X}_{6} \cdots \mathrm{C}_{6} \mathrm{Y}_{6}$ dimers were without a doubt $\mathrm{XB}$ complexes stabilized via two interactions of similar strengths. For instance, the $d_{\text {At }} \cdots$ C and the $d_{\text {At }} \cdots_{\text {I }}$ distances were approximately $5 \%$ shorter than the sum of the van der Waals radii in the complex ruled by At-XBs $(X=A t, Y=I)$. In the case of $X=I$ and $Y=A t$, these were the interaction angles that were very similar $\left(2.5^{\circ}\right.$ difference $)$.
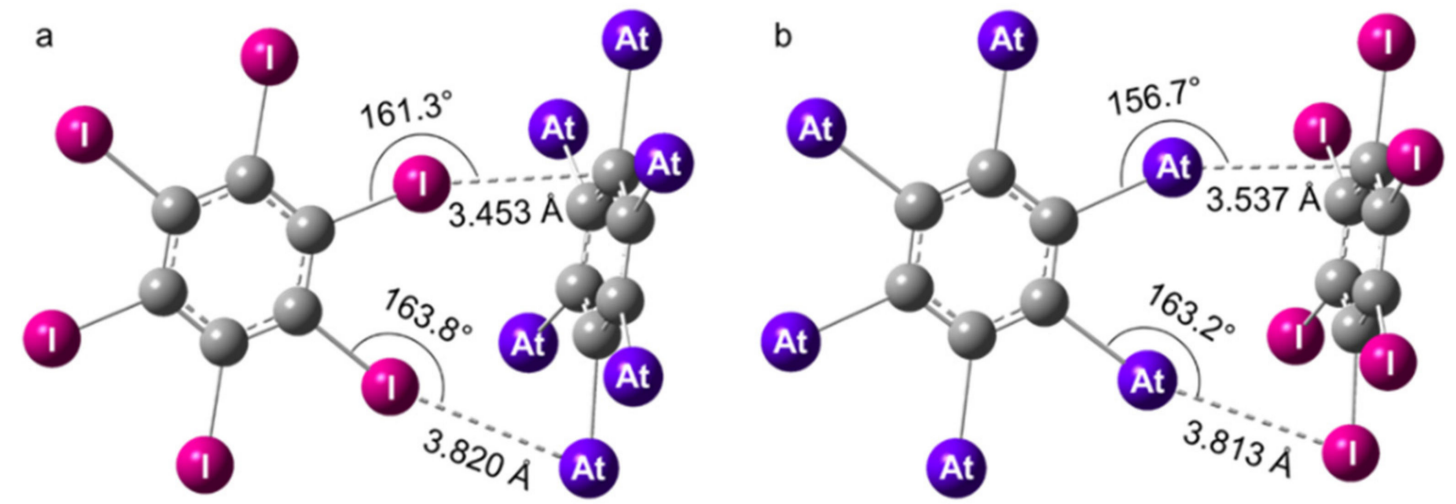

Figure 2. Structures of the $\mathrm{XB}$ complexes formed by $\mathrm{C}_{6} \mathrm{At}_{6}$ and $\mathrm{C}_{6} \mathrm{I}_{6}$ at the 2c-PW6B95-D3/TZVPPD level of theory. The $\mathrm{XB}$ interactions mediated by iodine $(X=I, Y=A t)$ are displayed on the left $(\mathbf{a})$ and the ones mediated by astatine $(X=A t, Y=I)$ on the right (b).

The most unusual and surprising result was that $\mathrm{C}_{6} \mathrm{At}_{6} \cdots \mathrm{C}_{6} \mathrm{I}_{6}$ was not more stable than $\mathrm{C}_{6} \mathrm{I}_{6} \cdots \mathrm{C}_{6} \mathrm{At}_{6}$, i.e., the $\mathrm{XBs}$ involving astatine were not stronger than their counterparts mediated by iodine. Indeed, the stabilization energy resulting from the two At-XBs in $\mathrm{C}_{6} \mathrm{At}_{6} \cdots \mathrm{C}_{6} \mathrm{I}_{6}$ was $-48.0 \mathrm{~kJ} / \mathrm{mol}$ at the 2c-PW6B95D3/TZVPPD level of theory, which is nearly equal to the total interaction energy due to the I-XBs in $\mathrm{C}_{6} \mathrm{I}_{6} \cdots \mathrm{C}_{6} \mathrm{At}_{6},-47.6 \mathrm{~kJ} / \mathrm{mol}$. The situation was even more unfavorable for At-XBs according to the 2c-MP2/TZVPPD calculations, the total interaction energy being $-52.7 \mathrm{~kJ} / \mathrm{mol}$, while the one for I-XBs was $-56.0 \mathrm{~kJ} / \mathrm{mol}$ (3.3 kJ/mol stronger). Even though the deviations for the computed interaction energies between the two theory levels (i.e., 2c-PW6B95D3/TZVPPD and 2cMP2/TZVPPD) can represent $8 \mathrm{~kJ} / \mathrm{mol}$, both methodologies agree on the tendency that XBs mediated by astatine may not be stronger than their iodine counterparts. This result is at variance with the general consensus that the most polarizable and less electronegative halogen elements form the strongest XBs $[2,18]$. As seen above, the C-At bonds in $\mathrm{C}_{6} \mathrm{At}_{6}$ exhibited a CS character that was enhanced by the relativistic spin-orbit interaction. Since the CS bonding weakened the local electrophilicity at the $\sigma$-hole (cf. Figure S1 in Supplementary Materials), the fact that At-XBs can become similar or weaker than their iodinated counterparts when the $\mathrm{SOC}$ is considered in the calculations reveals a connection to the $\mathrm{CS}$ character of the $\mathrm{C}-\mathrm{At}$ bonds. The CS bonding did not only diminish the $\mathrm{XB}$ donating ability of $\mathrm{C}_{6} \mathrm{At}_{6}$, but it possibly changed it into a weaker $\mathrm{XB}$ donor than $\mathrm{C}_{6} \mathrm{I}_{6}$.

A fundamental question arising from the above results is whether the observed behavior is specific to $\mathrm{C}_{6} \mathrm{At}_{6}$ or if it can occur with other halogenated aromatic compounds. In this framework, the case of borirene, $\mathrm{C}_{2} \mathrm{BH}_{3}$, is interesting to consider for several reasons. It is the smallest representative of neutral aromatic molecules, consisting of a three-membered heterocyclic ring [75]. Additionally, the perhalogenation with astatine leads to the formation of both C-At and B-At bonds, two types of bond on which are currently based the most advanced radiosynthetic protocols for the use of ${ }^{211} \mathrm{At}$ in targeted alpha therapy [76-78]. 


\section{4. $C_{2} B X_{3} \cdots C_{2} B Y_{3}$ Complexes}

In the $\mathrm{C}_{2} \mathrm{BX}_{3} \cdots \mathrm{C}_{2} \mathrm{BY}_{3}$ heterodimers, the stabilization can occur through $\mathrm{XB}$ interactions mediated by astatine $(X=A t, Y=I)$ or iodine $(X=I, Y=A t)$. The $X$ atom of the $X B$ donor is pointing towards the centroid of the aromatic $\pi$ system of the $\mathrm{C}_{2} \mathrm{BY}_{3}$ monomer. Since $X$ can be bound to a carbon atom or to the boron atom, four types of XBs were studied and the corresponding most stable structures are presented in Figure 3.

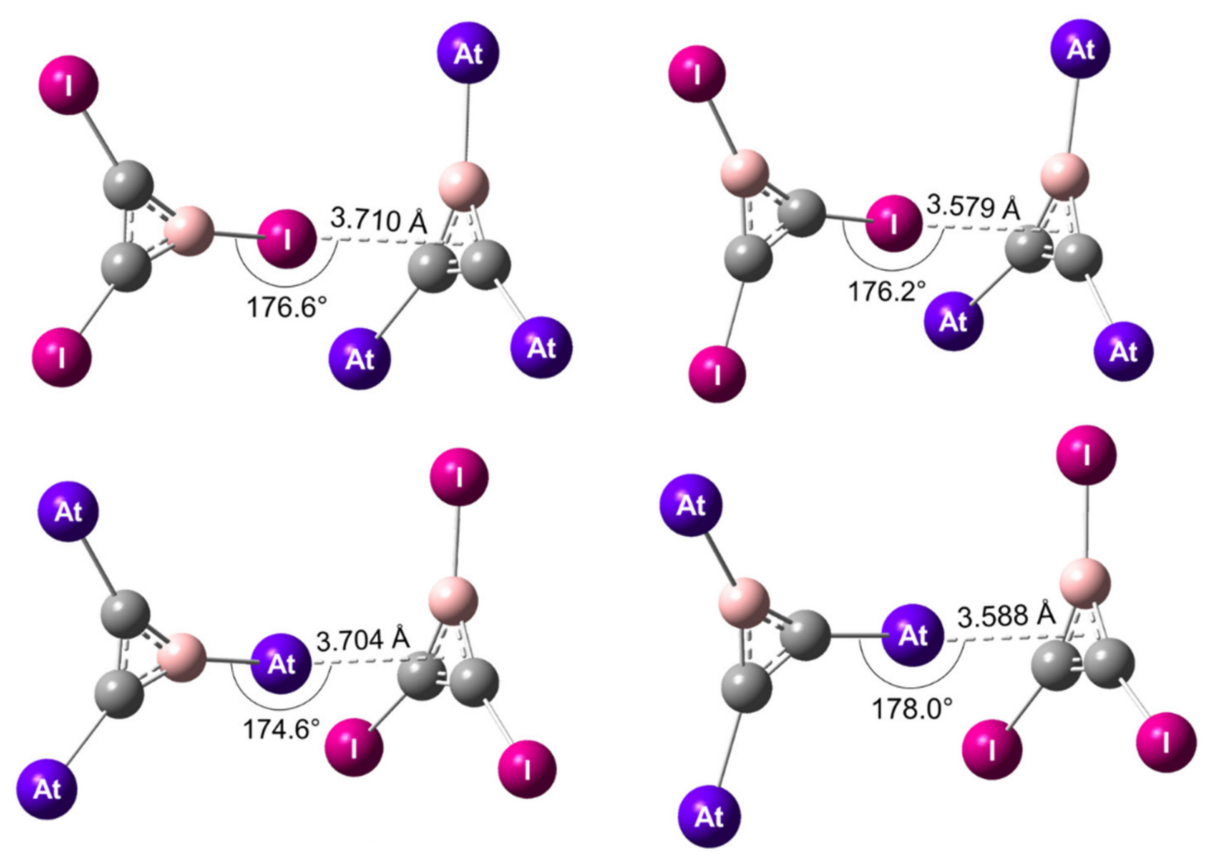

Figure 3. Structures of the $\mathrm{XB}$ complexes formed by $\mathrm{C}_{2} \mathrm{BI}_{3}$ and $\mathrm{C}_{2} \mathrm{BAt}_{3}$ at the 2c-PW6B95D3/TZVPPD level of theory. The $\mathrm{XB}$ interactions mediated by iodine $(X=\mathrm{I}, \mathrm{Y}=\mathrm{At})$ are displayed on top and the ones mediated by astatine $(X=A t, Y=I)$ on the bottom.

Note that the DFT geometries optimized at the scalar-relativistic level agree well with those obtained from counterpoise-corrected sr-MP2/TZVPPD calculations. The interaction distances were slightly longer, by $3 \%$ on average, and therefore the interaction energies were slightly weaker, by $\sim 1 \mathrm{~kJ} / \mathrm{mol}$ (cf. Table S3 in Supplementary Materials). According to the 2c-PW6B95-D3/TZVPPD results, all the $\mathrm{XB}$ complexes exhibited a $\mathrm{C}_{\mathrm{s}}$ symmetry. The angle between the $\mathrm{R}-\mathrm{X}$ bond $(\mathrm{R}=\mathrm{B}, \mathrm{C})$ and the centroid of the $\mathrm{C}_{2} \mathrm{BY}_{3}$ cycle was close to $180^{\circ}$, i.e., $R, X$, and the centroid were almost aligned (Figure 3 ). It is noteworthy to mention that the $\mathrm{XB}$ mediated by an iodine atom bound to the boron atom $\left(\mathrm{I}_{\mathrm{B}}-\mathrm{XB}\right)$ showed a longer interaction distance, $3.710 \AA$, than that of the $\mathrm{XB}$ mediated by iodine but bound to a carbon atom $\left(\mathrm{I}_{\mathrm{C}-} \mathrm{XB}\right), 3.579 \AA$. The same trend was noticed with the At-XBs. When the astatine atom was bound to carbon atoms, the $\mathrm{At}_{\mathrm{C}_{-} \mathrm{XB}} \mathrm{B}$ was $0.116 \AA$ shorter than the corresponding $A t_{B}-X B$, i.e., when astatine was bound to the boron atom. It supports stronger $I_{C}-X B$ and $A t_{C}-X B$ interactions with respect to their $\mathrm{I}_{B}-\mathrm{XB}$ and $A t_{B}-\mathrm{XB}$ counterparts, respectively.

The interaction energies of XB complexes at the 2c-PW6B95D3/TZVPPD and 2cMP2/TZVPD levels of theory are presented in Table 4. These energies are in line with the discussion based on the structural parameters: the interaction energy for the $\mathrm{I}_{\mathrm{C}-} \mathrm{XB}$ is computed approximately $2 \mathrm{~kJ} / \mathrm{mol}$ stronger than for the $\mathrm{I}_{\mathrm{B}}-\mathrm{XB}$. A similar difference was found between $\mathrm{At}_{\mathrm{C}}-\mathrm{XB}$ and $\mathrm{At}_{\mathrm{B}}-\mathrm{XB}$. This finding corroborates the general consensus that the more electron-withdrawing the $\mathrm{R}$ group bound to the $X$ halogen atom $(\chi(B)<\chi(C))$, the stronger the interaction with nucleophilic sites [10,79]. The $\mathrm{R}$ inductive effect manifests itself in particular at the halogen $\sigma$-hole in $\mathrm{C}_{2} \mathrm{BX}_{3}$ (Figure $\mathrm{S} 2$ in Supplementary Materials). $V_{\mathrm{S}, \max }$ was larger when I was bound to $\mathrm{C}$ atoms $(113.7 \mathrm{~kJ} / \mathrm{mol})$ rather than to the $\mathrm{B}$ atom $(72.4 \mathrm{~kJ} / \mathrm{mol})$, as $V_{\mathrm{S}, \max }$ was larger when At was bound to $C$ atoms $(134.7 \mathrm{~kJ} / \mathrm{mol})$ rather 
than to the B atom $(91.2 \mathrm{~kJ} / \mathrm{mol})$. The strongest interactions were therefore mediated by the halogens bound to $\mathrm{C}$ atoms.

Table 4. Counterpoise-corrected 2c-PW6B95D3/TZVPPD and 2c-MP2/TZVPPD interaction energies $\left(\triangle \mathrm{E}^{\mathrm{CP}}\right)$ of the $\mathrm{C}_{2} \mathrm{BX}_{3} \cdots \mathrm{C}_{2} \mathrm{BY}_{3}$ heterodimers with $\mathrm{X}, \mathrm{Y}=\mathrm{I}$, At.

\begin{tabular}{ccccc}
\hline $\boldsymbol{\Delta} \boldsymbol{E}^{\mathrm{CP}}(\mathbf{k J} / \mathbf{m o l})$ & $\mathbf{I}_{\mathbf{B}}-\mathbf{X B}$ & $\mathbf{I}_{\mathbf{C}-} \mathbf{X B}$ & $\mathbf{A t}_{\mathbf{B}}-\mathbf{X B}$ & $\mathbf{A t}_{\mathbf{C}-} \mathbf{X B}$ \\
\hline 2c-PW6B95-D3/TZVPPD & -13.7 & -15.8 & -13.9 & -15.6 \\
2c-MP2/TZVPPD & $-14.2^{\mathrm{a}}$ & $-16.7^{\mathrm{a}}$ & $-14.0^{\mathrm{a}}$ & $-15.9^{\mathrm{a}}$ \\
\hline a 2c-MP2/TZVPPD//2c-PW6B95-D3/TZVPPD calculations. & &
\end{tabular}

The next question was whether astatine in $\mathrm{C}_{2} \mathrm{BAt}_{3}$ or iodine in $\mathrm{C}_{2} \mathrm{BI}_{3}$ leads to the strongest $\mathrm{XB}$. According to the 2c-PW6B95-D3/TZVPPD calculations, the interaction energy for $\mathrm{At}_{\mathrm{C}-} \mathrm{XB}$ was $-15.6 \mathrm{~kJ} / \mathrm{mol}$, while the one corresponding to $\mathrm{I}_{\mathrm{C}-} \mathrm{XB}$ was $-15.8 \mathrm{~kJ} / \mathrm{mol}$, i.e., slightly better for iodine. The dominance of $\mathrm{C}_{2} \mathrm{BI}_{3}$ over $\mathrm{C}_{2} \mathrm{BAt}_{3}$ was slightly more pronounced at the 2c-MP2/TZVPPD level of theory, the $\mathrm{I}_{\mathrm{C}}-\mathrm{XB}$ interaction being $0.8 \mathrm{~kJ} / \mathrm{mol}$ stronger than its astatinated counterpart (Table 4). Note that these differences of interaction energies were less than $1 \mathrm{~kJ} / \mathrm{mol}$, which is lower than the usual accuracy of the methods used. However, both our DFT and ab initio calculations agreed on the same trend, which confirmed the previous results obtained on $\mathrm{XB}$ complexes between $\mathrm{C}_{6} \mathrm{I}_{6}$ and $\mathrm{C}_{6} \mathrm{At}_{6}$; the heaviest halogen element may not form stronger $\mathrm{XB}$ interactions than its lighter homologue. It must be stressed that this behavior cannot be anticipated from the value of the reactivity descriptors computed for $\mathrm{C}_{2} \mathrm{BAt}_{3}$ and $\mathrm{C}_{2} \mathrm{BI}_{3}$. Indeed, neither the comparison between computed $V_{\mathrm{S} \text {,max }}$ at the astatine and iodine $\sigma$-holes (Figure $\mathrm{S} 2$ in the Supplementary Materials) nor the comparison between computed $\omega^{+}$s,max at the astatine and iodine $\sigma$-holes (Figure S3 in the Supplementary Materials) allow one to predict if At-XB interactions will be stronger or weaker than the corresponding I-XBs. Here again, the "unexpected" behavior was observed provided that the spin-orbit interaction was taken into account in the relativistic calculations. Indeed, the relative stability between the $\mathrm{At}_{\mathrm{C}-} \mathrm{XB}$ and $\mathrm{I}_{\mathrm{C}-} \mathrm{XB}$ interactions was inverted by $\sim 0.9 \mathrm{~kJ} / \mathrm{mol}$, with respect to the sr results (Table S2 in the Supplementary Materials). Since SOC enhances the astatine propensity to form CS bonds [52,59] and C-At bonds can exhibit a significant CS character [32,52], it is unsurprising to notice in $\mathrm{C}_{2} \mathrm{BAt}_{3}$ a weakening of the local electrophilicity at the astatine's $\sigma$-hole. The $\omega^{+}{ }_{s, \max }$ value was reduced by $7 \%$ upon SOC (Figure S3 in the Supplementary Materials) and, consequently, the potential of astatine to accept charge transfers from $\mathrm{XB}$ acceptors.

In addition, the comparison between the interactions where the $\mathrm{X}$ halogen $(\mathrm{X}=\mathrm{I}$, At) was bound to the boron atom also revealed a similar behavior. First, the $\omega^{+}{ }_{S, \max }$ value at the $\sigma$-hole of the astatine atom bound to B decreased by $4 \%$ upon SOC (Figure S3 in the Supplementary Materials). The 2c-PW6B95D3/TZVPPD or 2c-MP2/TZVPPD calculations therefore led to analogous stabilities for $\mathrm{I}_{\mathrm{B}}-\mathrm{XB}$ and $\mathrm{At}_{\mathrm{B}}-\mathrm{XB}$ interactions, the energy difference being less than $0.2 \mathrm{~kJ} / \mathrm{mol}$ for a given level of theory (Table 4). Given the expected precision of the methods used, in these systems neither iodine nor astatine can be identified with certainty as the halogen mediating the strongest interaction.

\section{Conclusions}

In this work, the ability of $\mathrm{C}_{6} \mathrm{I}_{6}$ and $\mathrm{C}_{6} \mathrm{At}_{6}$ halobenzenes to form halogen-bond (XB) interactions was investigated by means of two-component relativistic quantum mechanical calculations. Although astatine is the less electronegative and the most polarizable of the halogen elements, it was shown that the strength of halogen bonds mediated by astatine (At-XBs) can be similar or weaker than one of their iodinated counterparts (I-XBs) when comparing complexes formed by $\mathrm{C}_{6} \mathrm{At}_{6}$ and $\mathrm{C}_{6} \mathrm{I}_{6}$. This behavior cannot be anticipated from the comparison between reactivity descriptors such as $V_{\mathrm{S}, \max }$ computed at the astatine and iodine $\sigma$-holes of each $\mathrm{XB}$ donor. Conversely, some rationale is actually gained thanks to QTAIM and ELF topological analyses of the electronic structure of $\mathrm{C}_{6} \mathrm{At}_{6}$. Astatine being the heaviest halogen element, in the computations, we used the relativistic effects as a tool 
to disclose the bonding patterns in the $\mathrm{C}_{6} \mathrm{At}_{6}$ species. According to previous results by Alvarez-Thon and co-workers [26], the topological descriptors testify to a strong electron delocalization. But above all, the C-At bonds demonstrate a significant charge-shift (CS) character. CS bonding is a mechanism that aims to minimize Pauli repulsion between the bonding electrons and the $\sigma$ lone-pair of astatine (referred to as the lone-pair bondweakening effect, LPBWE [63]). The spin-orbit coupling (SOC) is known to enhance the astatine propensity for CS bonding [25,52,59], and the CS component of C-At bonds in $\mathrm{C}_{6} \mathrm{At}_{6}$ is indeed increased upon inclusion of SOC in relativistic calculations. If $\sigma$ electrons suffer a stronger Pauli repulsion (LPBWE), the local electrophilicity at the astatine $\sigma$-hole is also significantly decreased, by $\sim 20 \%$ according to the $\omega^{+}$s,max value. This electrophilicity index is intended to probe the charge transfer contribution to the XB stabilization [31] and, indeed, the interactions were weakened with studied Lewis bases, according to two-component relativistic quantum mechanical calculations.

Signs of this connection between $\mathrm{XB}$ and $\mathrm{CS}$ bonding have been previously found in $\mathrm{XB}$ complexes involving either $\mathrm{At}_{2}$ or $\mathrm{CAt}_{4}[24,32]$. The significance of the CS character of bonds in these $\mathrm{XB}$ donors translates into a weakened electrophilicity at the astatine $\sigma$-hole, and eventually weaker interactions than those involving their iodinated counterparts, $\mathrm{I}_{2}$ and $\mathrm{CI}_{4}$. In ancient Roman myth, Janus is the god of beginnings and endings. Just as Janus presents two faces, astatine seems to have two antinomic characters. On the basis of the features given above (i.e., electronegativity, polarizability), astatine in R-At compounds should be the strongest XB donor atom. However, its ability for CS bonding, if operating within the R-At bond, then hinders the formation of XBs. An obvious manifestation of this ambivalence is to find weaker At-XBs than their I-XB analogues. Currently, a handful of examples have been characterized. But the possibility of widespread interplay between halogen bonding and charge-shift bonding remains to be demonstrated, both concerning astatine and other halogens such as fluorine.

Supplementary Materials: The following are available online. Figure S1: 2c-PW6B95D3/TZVPPD calculated electrostatic potential and local electrophilicity at the $\mathrm{C}_{6} \mathrm{At}_{6}$ and $\mathrm{C}_{6} \mathrm{I}_{6}$ molecular surfaces; Figure S2: 2c-PW6B95D3/TZVPPD calculated electrostatic potential at the $\mathrm{C}_{2} \mathrm{BI}_{3}$ and $\mathrm{C}_{2} \mathrm{BAt}_{3}$ molecular surfaces; Figure S3: Local electrophilicity calculated at the 2c-PW6B95D3/TZVPPD level of theory at the $\mathrm{C}_{2} \mathrm{BI}_{3}$ and $\mathrm{C}_{2} \mathrm{BAt}_{3}$ molecular surfaces; Table S1: Selected QTAIM descriptors obtained at the 2cPW6B95-D3/TZVPPD level of theory for $\mathrm{C}-\mathrm{C}$ bonds in $\mathrm{C}_{6} \mathrm{X}_{6}$ species $(\mathrm{X}=\mathrm{I}$, At); Table S2: Interaction distances, lengthening of $\mathrm{C}-\mathrm{X}$ bonds upon complexation, interaction angles, and directionality angles for the $\mathrm{C}_{6} \mathrm{X}_{6} \cdots \mathrm{C}_{6} \mathrm{Y}_{6}$ complexes $(\mathrm{X}, \mathrm{Y}=\mathrm{I}, \mathrm{At})$ at the counterpoise-corrected sr-MP2/TZVPPD level of theory; Table S3: Scalar relativistic PW6B95-D3/TZVPPD and MP2/TZVPPD counterpoise corrected interaction energies and related parameters: interaction distances, lengthening of $\mathrm{R}-\mathrm{X}$ bonds upon complexation $(\mathrm{R}=\mathrm{B}, \mathrm{C})$, and interaction angles, for the $\mathrm{C}_{2} \mathrm{BX}_{3} \cdots \mathrm{C}_{2} \mathrm{BY}_{3}$ complexes $(\mathrm{X}, \mathrm{Y}=\mathrm{I}, \mathrm{At})$.

Author Contributions: Conceptualization, S.S. and N.G.; methodology, S.S., J.P. and N.G.; investigation, S.S., J.P. and N.G.; data curation, S.S. and N.G.; writing—original draft preparation, S.S., J.-Y.L.Q. and N.G.; writing — review and editing, all authors; funding acquisition, G.M. and N.G. All authors have read and agreed to the published version of the manuscript.

Funding: This work has been supported in part by grants from the French National Agency for Research called "Programme d'Investissements d'Avenir" (ANR-11-EQPX-0004, ANR-11-LABX-0018, ANR-16-IDEX-0007) and from the "Région Pays de la Loire". It was carried out using HPC resources from CCIPL ("Centre de Calcul Intensif des Pays de la Loire").

Data Availability Statement: The data that support the findings of this study are available. Additional information can be requested from the corresponding author upon reasonable request.

Conflicts of Interest: The authors declare no conflict of interest. 


\section{References}

1. Politzer, P.; Murray, J.S.; Clark, T. Halogen Bonding and Other $\sigma$-Hole Interactions: A Perspective. Phys. Chem. Chem. Phys. 2013, 15, 11178-11189. [CrossRef]

2. Kolář, M.H.; Hobza, P. Computer Modeling of Halogen Bonds and Other $\sigma$-Hole Interactions. Chem. Rev. 2016, 116, 5155-5187. [CrossRef]

3. Parisini, E.; Metrangolo, P.; Pilati, T.; Resnati, G.; Terraneo, G. Halogen Bonding in Halocarbon-Protein Complexes: A Structural Survey. Chem. Soc. Rev. 2011, 40, 2267-2278. [CrossRef]

4. Lu, Y.; Liu, Y.; Xu, Z.; Li, H.; Liu, H.; Zhu, W. Halogen Bonding for Rational Drug Design and New Drug Discovery. Expert Opin. Drug Discov. 2012, 7, 375-383. [CrossRef]

5. Wilcken, R.; Zimmermann, M.O.; Lange, A.; Joerger, A.C.; Boeckler, F.M. Principles and Applications of Halogen Bonding in Medicinal Chemistry and Chemical Biology. J. Med. Chem. 2013, 56, 1363-1388. [CrossRef]

6. Mukherjee, A.; Tothadi, S.; Desiraju, G.R. Halogen Bonds in Crystal Engineering: Like Hydrogen Bonds yet Different. Acc. Chem. Res. 2014, 47, 2514-2524. [CrossRef]

7. Berger, G.; Soubhye, J.; Meyer, F. Halogen Bonding in Polymer Science: From Crystal Engineering to Functional Supramolecular Polymers and Materials. Polym. Chem. 2015, 6, 3559-3580. [CrossRef]

8. Bulfield, D.; Huber, S.M. Halogen Bonding in Organic Synthesis and Organocatalysis. Chem. Eur. J. 2016, 22, 14434-14450. [CrossRef] [PubMed]

9. Li, B.; Zang, S.-Q.; Wang, L.-Y.; Mak, T.C.W. Halogen Bonding: A Powerful, Emerging Tool for Constructing High-Dimensional Metal-Containing Supramolecular Networks. Coord. Chem. Rev. 2016, 308, 1-21. [CrossRef]

10. Cavallo, G.; Metrangolo, P.; Milani, R.; Pilati, T.; Priimagi, A.; Resnati, G.; Terraneo, G. The Halogen Bond. Chem. Rev. 2016, 116, 2478-2601. [CrossRef] [PubMed]

11. Riley, K.E.; Merz, K.M. Insights into the Strength and Origin of Halogen Bonding: The Halobenzene-Formaldehyde Dimer. J. Phys. Chem. A 2007, 111, 1688-1694. [CrossRef]

12. Lu, Y.-X.; Zou, J.-W.; Wang, Y.-H.; Jiang, Y.-J.; Yu, Q.-S. Ab Initio Investigation of the Complexes between Bromobenzene and Several Electron Donors: Some Insights into the Magnitude and Nature of Halogen Bonding Interactions. J. Phys. Chem. A 2007, 111, 10781-10788. [CrossRef]

13. Riley, K.E.; Murray, J.S.; Fanfrlík, J.; Řezáč, J.; Solá, R.J.; Concha, M.C.; Ramos, F.M.; Politzer, P. Halogen Bond Tunability I: The Effects of Aromatic Fluorine Substitution on the Strengths of Halogen-Bonding Interactions Involving Chlorine, Bromine, and Iodine. J. Mol. Model. 2011, 17, 3309-3318. [CrossRef] [PubMed]

14. Adasme-Carreño, F.; Muñoz-Gutierrez, C.; Alzate-Morales, J.H. Halogen Bonding in Drug-like Molecules: A Computational and Systematic Study of the Substituent Effect. RSC Adv. 2016, 6, 61837-61847. [CrossRef]

15. Tsuzuki, S.; Uchimaru, T.; Wakisaka, A.; Ono, T. Magnitude and Directionality of Halogen Bond of Benzene with $\mathrm{C}_{6} \mathrm{~F}_{5} \mathrm{X}, \mathrm{C}_{6} \mathrm{H}_{5} \mathrm{X}$, and $\mathrm{CF}_{3} \mathrm{X}(\mathrm{X}=\mathrm{I}, \mathrm{Br}, \mathrm{Cl}$, and F). J. Phys. Chem. A 2016, 120, 7020-7029. [CrossRef] [PubMed]

16. Chernysheva, M.V.; Bulatova, M.; Ding, X.; Haukka, M. Influence of Substituents in the Aromatic Ring on the Strength of Halogen Bonding in Iodobenzene Derivatives. Cryst. Growth Des. 2020, 20, 7197-7210. [CrossRef]

17. Otte, F.; Kleinheider, J.; Hiller, W.; Wang, R.; Englert, U.; Strohmann, C. Weak yet Decisive: Molecular Halogen Bond and Competing Weak Interactions of Iodobenzene and Quinuclidine. J. Am. Chem. Soc. 2021, 143, 4133-4137. [CrossRef] [PubMed]

18. Clark, T.; Hennemann, M.; Murray, J.S.; Politzer, P. Halogen Bonding: The $\sigma$-Hole. J. Mol. Model. 2007, 13, 291-296. [CrossRef]

19. Alkorta, I.; Blanco, F.; Solimannejad, M.; Elguero, J. Competition of Hydrogen Bonds and Halogen Bonds in Complexes of Hypohalous Acids with Nitrogenated Bases. J. Phys. Chem. A 2008, 112, 10856-10863. [CrossRef]

20. Hill, J.G.; Hu, X. Theoretical Insights into the Nature of Halogen Bonding in Prereactive Complexes. Chem. Eur. J. 2013, 19, 3620-3628. [CrossRef] [PubMed]

21. Wilbur, D.S. Enigmatic Astatine. Nat. Chem. 2013, 5, 246. [CrossRef]

22. Guo, N.; Maurice, R.; Teze, D.; Graton, J.; Champion, J.; Montavon, G.; Galland, N. Experimental and Computational Evidence of Halogen Bonds Involving Astatine. Nat. Chem. 2018, 10, 428-434. [CrossRef]

23. Liu, L.; Guo, N.; Champion, J.; Graton, J.; Montavon, G.; Galland, N.; Maurice, R. Towards a Stronger Halogen Bond Involving Astatine: Unexpected Adduct with $\mathrm{Bu}_{3}$ PO Stabilized by Hydrogen Bonding. Chem. Eur. J. 2020, 26, 3713-3717. [CrossRef]

24. Graton, J.; Rahali, S.; Questel, J.-Y.L.; Montavon, G.; Pilmé, J.; Galland, N. Spin-Orbit Coupling as a Probe to Decipher Halogen Bonding. Phys. Chem. Chem. Phys. 2018, 20, 29616-29624. [CrossRef]

25. Sarr, S.; Graton, J.; Rahali, S.; Montavon, G.; Galland, N. Delocalized Relativistic Effects, from the Viewpoint of Halogen Bonding. Phys. Chem. Chem. Phys. 2021, 23, 4064-4074. [CrossRef] [PubMed]

26. Ramírez-Tagle, R.; Alvarado-Soto, L.; Villavicencio-Wastavino, A.; Alvarez-Thon, L. Relativistic Effects on the Aromaticity of the Halogenated Benzenes: $\mathrm{C}_{6} \mathrm{X}_{6}, \mathrm{X}=\mathrm{H}, \mathrm{F}, \mathrm{Cl}, \mathrm{Br}, \mathrm{I}$, At. Phys. Chem. Chem. Phys. 2016, 18, 25751-25755. [CrossRef]

27. Mitin, A.V.; van Wüllen, C. Two-Component Relativistic Density-Functional Calculations of the Dimers of the Halogens from Bromine through Element 117 Using Effective Core Potential and All-Electron Methods. J. Chem. Phys. 2006, 124, 064305. [CrossRef]

28. Yang, D.-D.; Wang, F. Structures and Stabilities of Group 17 Fluorides $\mathrm{EF}_{3}$ (E = I, At, and Element 117) with Spin-Orbit Coupling. Phys. Chem. Chem. Phys. 2012, 14, 15816-15825. [CrossRef] [PubMed]

29. Frisch, M.J.; Trucks, G.W.; Schlegel, H.B.; Scuseria, G.E.; Robb, M.A.; Cheeseman, J.R.; Scalmani, G.; Barone, V.; Petersson, G.A.; Nakatsuji, H.; et al. Gaussian 16 Rev. A.03; Gaussian, Inc.: Wallingford, CT, USA, 2016. 
30. Sergentu, D.-C.; David, G.; Montavon, G.; Maurice, R.; Galland, N. Scrutinizing “Invisible” Astatine: A Challenge for Modern Density Functionals. J. Comput. Chem. 2016, 37, 1345-1354. [CrossRef]

31. Galland, N.; Montavon, G.; Questel, J.-Y.L.; Graton, J. Quantum Calculations of At-Mediated Halogen Bonds: On the Influence of Relativistic Effects. New J. Chem. 2018, 42, 10510-10517. [CrossRef]

32. Sarr, S.; Graton, J.; Montavon, G.; Pilmé, J.; Galland, N. On the Interplay between Charge-Shift Bonding and Halogen Bonding. ChemPhysChem 2020, 21, 240-250. [CrossRef]

33. Grimme, S.; Ehrlich, S.; Goerigk, L. Effect of the Damping Function in Dispersion Corrected Density Functional Theory. J. Comput. Chem. 2011, 32, 1456-1465. [CrossRef] [PubMed]

34. Peterson, K.A. Systematically Convergent Basis Sets with Relativistic Pseudopotentials. I. Correlation Consistent Basis Sets for the Post-d Group 13-15 Elements. J. Chem. Phys. 2003, 119, 11099-11112. [CrossRef]

35. Peterson, K.A.; Shepler, B.C.; Figgen, D.; Stoll, H. On the Spectroscopic and Thermochemical Properties of ClO, BrO, IO, and Their Anions. J. Phys. Chem. A 2006, 110, 13877-13883. [CrossRef]

36. Weigend, F.; Baldes, A. Segmented contracted basis sets for one- and two-component Dirac-Fock effective core potentials. J. Chem. Phys. 2010, 133, 174102. [CrossRef]

37. Weigend, F.; Ahlrichs, R. Balanced basis sets of split valence, triple zeta valence and quadruple zeta valence quality for $H$ to Rn: Design and assessment of accuracy. Phys. Chem. Chem. Phys. 2005, 7, 3297-3305. [CrossRef] [PubMed]

38. Rappoport, D.; Furche, F. Property-optimized Gaussian basis sets for molecular response calculations. J. Chem. Phys. 2010, 133, 134105. [CrossRef] [PubMed]

39. Boys, S.; Bernardi, F. The calculation of small molecular interactions by the differences of separate total energies. Some procedures with reduced errors. Mol. Phys. 1970, 19, 553-566. [CrossRef]

40. TURBOMOLE. A Development of University of Karlsruhe and Forschungszentrum Karlsruhe GmbH, 1989-2007, TURBOMOLE $\mathrm{GmbH}$, Since 2007. Available online: http:/ / www.turbomole.com (accessed on 30 June 2021).

41. Chattaraj, P.K.; Sarkar, A.U.; Roy, D.R. Electrophilicity Index. Chem. Rev. 2006, 106, 2065-2091. [CrossRef]

42. Becke, A.D.; Edgecombe, E.K. A simple measure of electron localization in atomic and molecular systems. J. Chem. Phys. 1990, 92, 5397-5403. [CrossRef]

43. Silvi, B.; Savin, A. Classification of chemical bonds based on topological analysis of electron localization functions. Nat. Cell Biol. 1994, 371, 683-686. [CrossRef]

44. Gillespie, R.J.; Robinson, E.A. Gilbert N. Lewis and the chemical bond: The electron pair and the octet rule from 1916 to the present day. J. Comput. Chem. 2006, 28, 87-97. [CrossRef]

45. Llusar, R.; Beltrán, A.; Andrés, J.; Noury, S.; Silvi, B. Topological analysis of electron density in depleted homopolar chemical bonds. J. Comput. Chem. 1999, 20, 1517-1526. [CrossRef]

46. Bader, R.F.W. Atoms in Molecules: A Quantum Theory; International Series of Monographs on Chemistry; Oxford University Press: New York, NY, USA, 1994; ISBN 978-0-19-855865-1.

47. Koritsanszky, T.S.; Coppens, P. Chemical Applications of X-ray Charge-Density Analysis. Chem. Rev. 2001, 101, 1583-1628. [CrossRef]

48. Matta, C.F.; Boyd, R.J. The Quantum Theory of Atoms in Molecules: From Solid State to DNA and Drug Design; John Wiley \& Sons: Hoboken, NJ, USA, 2007; ISBN 978-3-527-61069-3.

49. Bader, R.F.W.; Essen, H. The characterization of atomic interactions. J. Chem. Phys. 1984, 80, 1943-1960. [CrossRef]

50. Matta, C.F.; Boyd, R.J. An Introduction to the Quantum Theory of Atoms in Molecules. In The Quantum Theory of Atoms in Molecules; John Wiley \& Sons, Ltd.: Hoboken, NJ, USA, 2007; pp. 1-34. ISBN 978-3-527-61070-9.

51. Fradera, X.; Poater, J.; Simon, S.; Duran, M.; Solà, M. Electron-pairing analysis from localization and delocalization indices in the framework of the atoms-in-molecules theory. Theor. Chem. Accounts 2002, 108, 214-224. [CrossRef]

52. Pilmé, J.; Renault, E.; Bassal, F.; Amaouch, M.; Montavon, G.; Galland, N. QTAIM Analysis in the Context of Quasirelativistic Quantum Calculations. J. Chem. Theory Comput. 2014, 10, 4830-4841. [CrossRef]

53. Pilmé, J.; Renault, E.; Ayed, T.; Montavon, G.; Galland, N. Introducing the ELF Topological Analysis in the Field of Quasirelativistic Quantum Calculations. J. Chem. Theory Comput. 2012, 8, 2985-2990. [CrossRef] [PubMed]

54. Kozlowski, D.; Pilmé, J. New insights in quantum chemical topology studies using numerical grid-based analyses. J. Comput. Chem. 2011, 32, 3207-3217. [CrossRef]

55. Amaouch, M.; Montavon, G.; Galland, N.; Pilmé, J. What can tell the quantum chemical topology on carbon-Astatine bonds? Mol. Phys. 2015, 114, 1326-1333. [CrossRef]

56. Amaouch, M.; Renault, E.; Montavon, G.; Galland, N.; Pilmé, J. Quantum Chemical Topology in the Field of Qua-sirelativistic Quantum Calculations. In Applications of Topological Methods in Molecular Chemistry; Challenges and Advances in Computational Chemistry and Physics; Chauvin, R., Lepetit, C., Silvi, B., Alikhani, E., Eds.; Springer: Berlin/Heidelberg, Germany, 2016; pp. 553-582. ISBN 978-3-319-29022-5.

57. Ayed, T.; Pilmé, J.; Teze, D.; Bassal, F.; Barbet, J.; Chérel, M.; Champion, J.; Maurice, R.; Montavon, G.; Galland, N. 211 At-labeled agents for alpha-immunotherapy: On the in vivo stability of astatine-agent bonds. Eur. J. Med. Chem. 2016, 116, 156-164. [CrossRef] [PubMed]

58. Amaouch, M.; Sergentu, D.-C.; Steinmetz, D.; Maurice, R.; Galland, N.; Pilmé, J. The bonding picture in hypervalent $X F 3(X=C l$, $\mathrm{Br}$, I, At) fluorides revisited with quantum chemical topology. J. Comput. Chem. 2017, 38, 2753-2762. [CrossRef] [PubMed] 
59. Pech, C.G.; Haase, P.A.B.; Sergentu, D.; Borschevsky, A.; Pilmé, J.; Galland, N.; Maurice, R. Quantum chemical topology at the spin-orbit configuration interaction level: Application to astatine compounds. J. Comput. Chem. 2020, 41, 2055-2065. [CrossRef]

60. Noury, S.; Colonna, F.; Savin, A.; Silvi, B. Analysis of the delocalization in the topological theory of chemical bond. J. Mol. Struct. 1998, 450, 59-68. [CrossRef]

61. Savin, A.; Silvi, B.; Colonna, F. Topological analysis of the electron localization function applied to delocalized bonds. Can. J. Chem. 1996, 74, 1088-1096. [CrossRef]

62. Shaik, S.; Maitre, P.; Sini, G.; Hiberty, P.C. The charge-shift bonding concept. Electron-pair bonds with very large ionic-covalent resonance energies. J. Am. Chem. Soc. 1992, 114, 7861-7866. [CrossRef]

63. Shaik, S.; Danovich, D.; Wu, W.; Hiberty, P.C. Charge-shift bonding and its manifestations in chemistry. Nat. Chem. 2009, 1, 443-449. [CrossRef]

64. Shaik, S.; Danovich, D.; Silvi, B.; Lauvergnat, D.L.; Hiberty, P.C. Charge-Shift Bonding-A Class of Electron-Pair Bonds That Emerges from Valence Bond Theory and Is Supported by the Electron Localization Function Approach. Chem. Eur. J. 2005, 11, 6358-6371. [CrossRef]

65. Outeiral, C.; Vincent, M.A.; Pendás, M.; Popelier, P.L.A. Revitalizing the concept of bond order through delocalization measures in real space. Chem. Sci. 2018, 9, 5517-5529. [CrossRef] [PubMed]

66. Silvi, B.; Gillespie, R.J.; Gatti, C. Electron Density Analysis. In Comprehensive Inorganic Chemistry II, 2nd ed.; Reedijk, J., Poeppelmeier, K., Eds.; Elsevier: Amsterdam, The Netherlands, 2013; pp. 187-226. ISBN 978-0-08-096529-1.

67. Zhang, L.; Ying, F.; Wu, W.; Hiberty, P.C.; Shaik, S. Topology of Electron Charge Density for Chemical Bonds from Valence Bond Theory: A Probe of Bonding Types. Chem. Eur. J. 2009, 15, 2979-2989. [CrossRef]

68. Réal, F.; Gomes, A.S.P.; Martínez, Y.O.G.; Ayed, T.; Galland, N.; Masella, M.; Vallet, V. Structural, dynamical, and transport properties of the hydrated halides: How do At- bulk properties compare with those of the other halides, from F- to I-? J. Chem. Phys. 2016, 144, 124513. [CrossRef]

69. Cremer, D.; Kraka, E. Chemical Bonds without Bonding Electron Density? Does the Difference Electron-Density Analysis Suffice for a Description of the Chemical Bond? Angew. Chem. Int. Ed. 1984, 23, 627-628. [CrossRef]

70. Mantina, M.; Chamberlin, A.C.; Valero, R.; Cramer, C.; Truhlar, D.G. Consistent van der Waals Radii for the Whole Main Group. J. Phys. Chem. A 2009, 113, 5806-5812. [CrossRef]

71. Meyer, E.A.; Castellano, R.K.; Diederich, F. Interactions with Aromatic Rings in Chemical and Biological Recognition. Angew. Chem. Int. Ed. 2003, 42, 4120. [CrossRef]

72. Hoeben, F.J.M.; Jonkheijm, P.; Meijer, E.W.; Schenning, A.P.H.J. About Supramolecular Assemblies of $\pi$-Conjugated Systems. Chem. Rev. 2005, 105, 1491-1546. [CrossRef] [PubMed]

73. Černý, J.; Hobza, P. Non-covalent interactions in biomacromolecules. Phys. Chem. Chem. Phys. 2007, 9, 5291-5303. [CrossRef] [PubMed]

74. Pitoňák, M.; Neogrády, P.; Řezáč, J.; Jurečka, P.; Urban, M.; Hobza, P. Benzene Dimer: High-Level Wave Function and Density Functional Theory Calculations. J. Chem. Theory Comput. 2008, 4, 1829-1834. [CrossRef]

75. Balucani, N.; Asvany, O.; Lee, A.Y.T.; Kaiser, R.I.; Galland, N.; Hannachi, Y. Observation of Borirene from Crossed Beam Reaction of Boron Atoms with Ethylene. J. Am. Chem. Soc. 2000, 122, 11234-11235. [CrossRef]

76. Wilbur, D. [211At]Astatine-Labeled Compound Stability: Issues with Released [211At]Astatide and Development of Labeling Reagents to Increase Stability. Curr. Radiopharm. 2008, 1, 144-176. [CrossRef]

77. Vaidyanathan, G.; Zalutsky, M.R. Applications of 211At and 223Ra in Targeted Alpha-Particle Radiotherapy. Curr. Radiopharm. 2011, 4, 283-294. [CrossRef]

78. Meyer, G.-J. Astatine. J. Label. Compd. Radiopharm. 2018, 61, 154-164. [CrossRef] [PubMed]

79. Politzer, P.; Murray, J.S.; Clark, T. Halogen bonding: An electrostatically-driven highly directional noncovalent interaction. Phys. Chem. Chem. Phys. 2010, 12, 7748-7757. [CrossRef] [PubMed] 